\title{
Combining Niche Modelling, Land-Use Change, and Genetic Information to Assess the Conservation Status of Pouteria splendens Populations in Central Chile
}

\author{
Narkis S. Morales, ${ }^{1,2}$ Ignacio C. Fernández, ${ }^{2,3}$ Basilio Carrasco, ${ }^{4}$ and Cristina Orchard ${ }^{2}$ \\ ${ }^{1}$ Department of Biological Sciences, Faculty of Science and Engineering, Macquarie University, Building E8B, Room 206, Sydney, \\ NSW 2109, Australia \\ ${ }^{2}$ Ecomabi Foundation, Ahumada 312, Oficina 425, 8320185 Santiago, Chile \\ ${ }^{3}$ Landscape Ecology \& Sustainability Laboratory, Arizona State University, LSE Building, Room 704, Tempe, AZ 85287, USA \\ ${ }^{4}$ Department of Crop Sciences, Faculty of Agronomy and Forestry Engineering, Pontifical Catholic University of Chile, \\ Avenida Vicuña Mackenna 4860, San Joaquin, 7820436 Santiago, Chile \\ Correspondence should be addressed to Ignacio C. Fernández; ignacio.fernandez@asu.edu
}

Received 9 June 2015; Revised 11 October 2015; Accepted 19 October 2015

Academic Editor: Ram Chander Sihag

Copyright (C) 2015 Narkis S. Morales et al. This is an open access article distributed under the Creative Commons Attribution License, which permits unrestricted use, distribution, and reproduction in any medium, provided the original work is properly cited.

\begin{abstract}
To assess the conservation status of a species with little ecological information is usually a challenging process. Pouteria splendens is an endemic shrub of the coastal range of Central Chile currently classified as lower risk (LR) by IUCN (version 2.3). Knowledge about this species is extremely limited. Currently P. splendens is only found in two small and isolated populations, which are thought to be remaining populations of an originally large metapopulation. However, there is no evidence to support this hypothesis, limiting our ability to gauge the real current conservation status of this species. In this study we combine niche modelling, landuse information, and genetic techniques to test the metapopulation hypothesis and reassess the conservation status of $P$. splendens using the IUCN criteria. We also evaluated the potential effects of climate change in the species distribution. Our results support the hypothesis of a large metapopulation that was recently fragmented. Future climate could increase the range of $P$. splendens; however the high level of fragmentation would preclude colonization processes. We recommend reclassifying $P$. splendens as Endangered (EN) and developing strategies to protect the remaining populations. Similar approaches like the presented here could be used to reclassify other species with limited ecological knowledge.
\end{abstract}

\section{Introduction}

Pouteria splendens (A.DC.) Kuntze (common name: lúcumo chileno, palo colorado) is an endemic shrub of the coastal areas of Central Chile and is the only representative of the Sapotaceae family in Chile [1]. P. splendens is an evergreen shrub, usually no taller than 2 meters, and with an intricate branching physiognomy. However, if conditions are favorable, individuals can develop longer trunks and reach more than 5 meters in height [2].

Historic records for $P$. splendens indicate a distribution that ranged from the coastal areas near the village of Huentelauquén $\left(31^{\circ} 36^{\prime} 24^{\prime \prime} \mathrm{S} ; 71^{\circ} 32^{\prime} 10^{\prime \prime} \mathrm{O}\right)$ in the north to the beach resort of Algarrobo $\left(33^{\circ} 22^{\prime} 50^{\prime \prime} \mathrm{S} ; 71^{\circ} 40^{\prime} 57^{\prime \prime} \mathrm{O}\right)$ to the south, extending continuously for near $200 \mathrm{~km}$ along the coastal range of Central Chile [2]. However, the current distribution is reported to be restricted to just two main populations isolated from each other by approximately $100 \mathrm{~km}$ [2]. Among these, the northern area has the larger population, covering an important proportion of the coastal terrace between north of Pichidangui $\left(32^{\circ} 08^{\prime} 19^{\prime \prime} \mathrm{S} ; 71^{\circ} 31^{\prime} 46^{\prime \prime} \mathrm{O}\right)$ and south of Los Molles $\left(32^{\circ} 14^{\prime} 15^{\prime \prime} \mathrm{S} ; 71^{\circ} 30^{\prime} 52^{\prime \prime} \mathrm{O}\right)$. The southern area is represented by a few isolated groups of individuals located on coastal cliffs and ravines between the coastal villages of Laguna Verde $\left(33^{\circ} 06^{\prime \prime} 05^{\prime} \mathrm{S} ; 71^{\circ} 40^{\prime \prime} 00^{\prime} \mathrm{O}\right)$ and Quintay $\left(33^{\circ} 11^{\prime \prime} 38^{\prime} S ; 71^{\circ} 41^{\prime \prime} 56^{\prime} \mathrm{O}\right)$. 
Current knowledge about $P$. splendens populations is extremely scarce, and until now much of the literature is based on historical presence records and anecdotal reports. For example, although available literature suggests that current populations are the remnants of a larger metapopulation covering the entire range of the historic distribution $[1,2]$, at present there is no empirical evidence, besides the historical presence records, that supports this hypothesis. The lack of information regarding $P$. splendens is also illustrated by the inconsistencies among authors or institutions in relation to its conservation status. Whereas Squeo et al. [3] and Hechenleitner et al. [2] classified the species as Critically Endangered, the Chilean species inventory system has listed it as Endangered [4] and the International Union for Conservation of Nature (IUCN) as Lower Risk/Near Threatened [5]. However, these classifications are based on different IUCN criteria (before and after 2001) which make them impossible to compare.

Among the main probable factors responsible for the reduction of $P$. splendens geographical range are the loss and fragmentation of original habitat due to the development of coastal resorts, towns, and cities that now cover most of original range of its distribution [2]. Alongside habitat loss, the local extinction of large animals capable of dispersing $P$. splendens seeds may have reduced the probability of these seeds to find new suitable sites for germination $[6,7]$. Additionally, the increasing frequency of droughts experienced by these areas due to climate change $[8,9]$ may have reduced $P$. splendens germination rates $[2,7]$ and increased its vulnerability to local extinctions due to an increment in fire regimes [10]. Climatic conditions are expected to keep changing along the distribution range of $P$. splendens [11], which may generate additional burdens for the preservation of remaining populations. Moreover, genetic diversity could decrease in fragmented populations as a consequence of genetic drift, inbreeding, bottlenecks, and founder effects, which together with demographic and environmental fluctuations may undermine the persistence of populations in the long run [12].

Even though remaining populations are increasingly threatened by human actions, currently none of the $P$. splendens populations have been covered by the Chilean system of national parks and protected areas (SNASPE), nor have they been included by any kind of public or private effective protection or conservation strategies. This lack of action has occurred even though the northern range of $P$. splendens distribution was officially recognized as an urgent site for conservation one decade ago [13].

Past studies on $P$. splendens have mainly focused on the species autoecology (i.e., $[6,7,14,15]$ ), and until now there have been no studies at larger scales that may provide answers to the original metapopulation hypothesis. This lack of information is not only limiting our understanding about potential causes of the current fragmented distribution of $P$. splendens populations, but also limiting our ability to gauge the urgency to develop conservation efforts.

The combination of spatially explicit ecological tools such as species niche modelling (e.g., [16-18]) and conservation genetics techniques (e.g., $[19,20])$ may provide critical information regarding species original distribution. Furthermore, the increasing availability of spatial land-use databases can offer key insights into the main past causes of population degradation, whereas the development of future climate models may provide valuable information regarding population potential future trends. Combining and evaluating this information should be taken as major task prior to developing conservation strategies for threatened species [21].

In order to reduce the knowledge gap regarding $P$. splendens past and current populations and to provide insightful knowledge that can be used for developing planning efforts towards its conservation, in this study we had five main objectives: (1) estimate the potential original distribution range of $P$. splendens by using a niche modelling approach, (2) evaluate potential trends of $P$. splendens populations under a probable future climate change scenario, (3) evaluate the role of land-use change in current and future species distribution, (4) assess intra- and interpopulation genetic diversity in order to evaluate the hypothesis of an original large continuous population, and (5) assess its current IUCN conservation status using this generated data.

\section{Materials and Methods}

2.1. Study Area. The study area covered the coastal range of North Central Chile (Figure 1), which is the historical reported distribution range of $P$. splendens $[2,7]$. This area can be broadly characterized as having a Mediterranean climate, with colder temperatures and rainy periods during winter months and warmer and drier conditions during summer period [22]. Annual average precipitation within this area ranges from $\sim 180 \mathrm{~mm}$ to $\sim 400 \mathrm{~mm}$ in an increasing gradient north-to-south, but monthly distribution of precipitation follows the same pattern in the whole range, with July being the wettest month and February the driest. Temperatures are relatively similar for the entire study area, with a mean annual temperature of $\sim 13^{\circ} \mathrm{C}$, where July is the coldest month $\left(\sim 10.5^{\circ} \mathrm{C}\right)$ and January the warmest $\left(\sim 17^{\circ} \mathrm{C}\right)$ [23]. Vegetation within this area is characterized by a predominance of shrub species that are directly influenced by oceanic conditions, with only occasional presence of forest patches, mainly in creeks and valleys facing southern slopes [24].

2.2. P. splendens Population Surveys. A total of 22 presence data points of $P$. splendens were used in our study. From these, 21 points were collected from herbarium records of the Chilean National Herbarium (SGO) and from the University of Concepción Herbarium (CONC). Records were georeferenced and visited on several field trips during the spring of 2010. We also visited other potential sites having the species, basing our search on satellite imaging interpretation and personal communications. A 22nd presence point was registered during the field trip, representing a small population not previously recorded (see Supplementary Material 1 in Supplementary Material available online at http://dx.doi.org/10.1155/2015/612194). For all the sites where established individuals were found, we estimated abundance based on a $\sim 30$ minute walking visual inspection. 


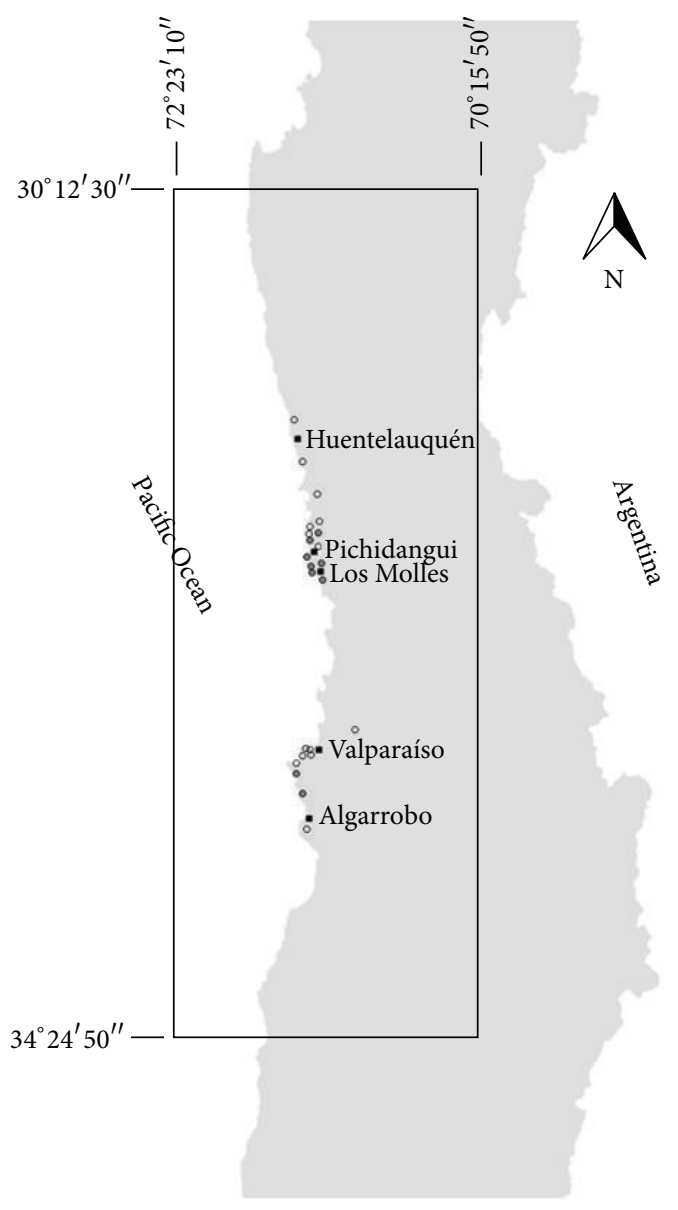

FIgURE 1: Area of study. The area of study covers the coastal areas of Central Chile. Historical presence records for P. splendens go from the coastal village of Huentulauquén to the beach resort of Algarrobo. Dots respresent recorded presence for the species; filled dots are those for which we found in-site current presence of individuals. The black rectangle indicates the area magnified in the binary distibution maps shown in Figure 2.

2.3. P. splendens Potential Habitat Modelling. To model the potential habitat distribution of $P$. splendens we used the principle of maximum entropy, which is part of the software MaxEnt [16]. MaxEnt estimates the probability of occurrence of the species of interest using presence only data and a group of environmental variables. We decided to use MaxEnt because it has been proven to be one of the best performing modelling methods available [25], it is reliable even with a small number of samples [26], and it is freely available. All the habitat distribution models were performed using MaxEnt version 3.3.3k (http://www.cs.princeton.edu/ schapire/maxent/).

Environmental variables for modelling were gathered from the WorldClim database. This database consists of a set of 19 global climatic layers generated by the interpolation of global climatic data such as average and seasonal temperature and precipitation [27]. We used the climatic data corresponding to the period from 1950 to 2000 , with a resolution of approximately $1 \mathrm{Km}^{2}$.
TABLE 1: Bioclimatic variables from WorldClim database. The variables in bold type were chosen to model the distribution of $P$. splendens after Pearson correlation analysis.

\begin{tabular}{lc}
\hline Variable & $\begin{array}{c}\text { Model } \\
\text { contribution } \\
(\%)\end{array}$ \\
\hline Annual Mean Temperature (Bio 1) & - \\
Mean Diurnal Range (Bio 2) & - \\
Isothermality (Bio 3) & $\mathbf{2 2 . 4 ^ { * }}$ \\
Temperature Seasonality (Bio 4) & $\mathbf{1 4 . 4 ^ { * }}$ \\
Max Temperature of Warmest Month (Bio 5) & - \\
Minimum Temperature of Coldest Month (Bio 6) & $\mathbf{6 2 . 7 ^ { * }}$ \\
Temperature Annual Range (Bio 7) & $\mathbf{0 . 3}$ \\
Mean Temperature of Wettest Quarter (Bio 8) & - \\
Mean Temperature of Driest Quarter (Bio 9) & - \\
Mean Temperature of Warmest Quarter (Bio 10) & - \\
Mean Temperature of Coldest Quarter (Bio 11) & - \\
Annual Precipitation (Bio 12) & $<\mathbf{0 . 1}$ \\
Precipitation of Wettest Month (Bio 13) & - \\
Precipitation of Driest Month (Bio 14) & $\mathbf{0 . 1}$ \\
Precipitation Seasonality (Bio 15) & - \\
Precipitation of Wettest Quarter (Bio 16) & - \\
Precipitation of Driest Quarter (Bio 17) & - \\
Precipitation of Warmest Quarter (Bio 18) & $<\mathbf{0 . 1}$ \\
Precipitation of Coldest Quarter (Bio 19) & $<\mathbf{0 . 1}$ \\
\hline
\end{tabular}

${ }^{*}$ The most relevant variables explaining the current distribution of $P$. splendens.

Considering the level of spatial resolution of the environment data layers and to avoid pseudo replication, we checked that our 22 P. splendens presence records were at least $1 \mathrm{~km}$ apart. Additionally, to reduce the potential of model overparameterization [28], we performed (Pearson) correlation analysis of the 19 bioclimatic variables, evaluating all pairs of variables with levels of correlation higher than $0.8(r>$ 0.8 ) and keeping only those variables that were biologically significant or easier to interpret. The correlation analyses were performed using the software ENMTools version 1.4.4 $[29,30]$. After the correlation analysis only 8 out the 19 bioclimatic variables were used for distribution modelling (Table 1).

We did not use the default configuration provided by MaxEnt for small samples (i.e., autofeatures) as recent studies have shown that this configuration would not be the most appropriate in some cases (e.g., [28, 31]), especially when dealing with a small number of samples $(<20-25)$ [32], as it was in our case. Therefore, to determine the optimal parameters to configure MaxEnt we compared different models with a combination of the "feature class" and "regularization multiplier" parameters recommended when dealing with small number of samples [32]. MaxEnt provides different types of restrictions ("feature class") in the modelling stage such as lineal $(\mathrm{L})$, quadratic $(\mathrm{Q})$, product $(\mathrm{P})$, threshold $(\mathrm{T})$, and hinge $(\mathrm{H})$ [16]. We used the following combinations 

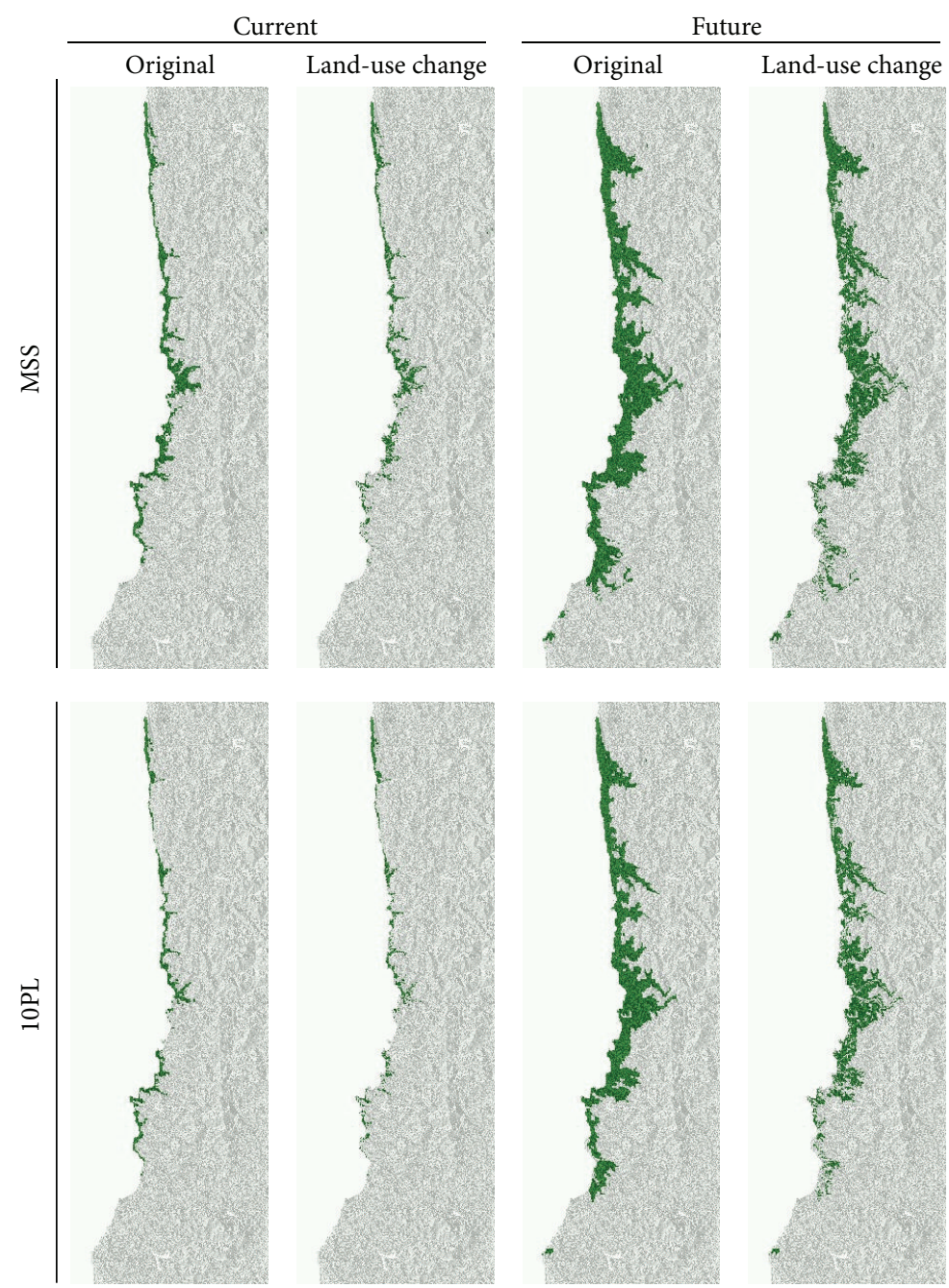

FIGURE 2: Binary maps showing potential habitat (green) of P. splendens with or without land-use change under current climate (years 1950 to 2000) and under future climate change scenario (RCP 6.0) (years 2041 to 2060). Two different thresholds were used to generate the binary maps, maximum sensitivity plus specificity (MSS) and 10 percentile training presence (10PL).

of these features: $\mathrm{L}, \mathrm{H}, \mathrm{LQ}$, and $\mathrm{LQH}$. The regularization multiplier values used were based on Warren and Seifert [30]: $1,2,5,10,15$, and 20 . All the models were compared using the corrected Akaike information criterion (AICc) [30], using for this process the software ENMTOOLS version 1.4.4 [29]. The results suggested that the best combination of parameters was LQ with a regularization multiplier of 1 (see Supplementary Material 2).

Once the optimal parameters were determined, we analyzed the performance of the model of choice using the method proposed by Pearson et al. [26] for models with a small number of samples. The method consists of a jackknife procedure that removes one presence point from the original dataset $(n=22)$ to subsequently run the model with the remainder $(n-1,21$ points) presence points. This process is repeated with all the available presence data points, generating 22 different models. Later, the model performance was analyzed using a prediction success rate and a $p$ value using the software "pValuecompute v.1.0" provided by Pearson et al. [26].
We produced binary maps using two different thresholds to define the suitable versus nonsuitable habitat. We used the "maximum sensitivity plus specificity logistic (MSS)" and the "10 percentile training presence logistic (10PL)" thresholds (values of 0.375 and 0.507 , resp.). We used these parameters as they are among the two most commonly used thresholds for creating binary suitability maps for species distribution with MaxEnt (e.g., [26, 33-35]).

2.4. P. splendens Potential Habitat Modelling under Climate Change. To predict potential changes in the habitat distribution of $P$. splendens under a hypothetical climate change scenario, we reprojected the model generated in the previous methodological section using a new environmental layer from the period (2041-2060). We used the climatic projections from the General Circulation Model (GCM) from the United Kingdom Meteorological Office Hadley Centre known as HadGEM2-ES [36]. The new climatic layers were downscaled and calibrated (bias corrected) using WorldClim 1.4 as baseline "current" climate [27]. We used the RCP 6.0 
TABLE 2: Genetic variability parameters obtained from 147 bands in 121 individuals of $P$. splendens ( $N$ : number of individuals sampled per area; I: Shannon's index; He: expected heterozygosity; P (\%): percentage of polymorphic loci).

\begin{tabular}{lcccc}
\hline Area & $N$ & $I$ & $\mathrm{He}$ & $\mathrm{P}(\%)$ \\
\hline Palo Colorado (PC) & 48 & $0.40 \pm 0.01$ & $0.24 \pm 0.01$ & 100 \\
Pichidangui-Los Molles (PM) & 43 & $0.35 \pm 0.01$ & $0.21 \pm 0.01$ & 99.32 \\
Caleta Quintay (CQ) & 30 & $0.35 \pm 0.01$ & $0.21 \pm 0.01$ & 98.64 \\
\hline
\end{tabular}

moderate scenario of representative concentration pathways (RCP) of greenhouse gases as it is considered the most plausible scenario under the current conditions [37]. We used the same bioclimatic variables utilized to build the habitat distribution model under the "current" climatic conditions. Binary maps for projected future potential distribution were generated using the same thresholds and approaches used to build the current conditions maps.

2.5. Land-Use Change Mapping. To estimate the historical land-use change that has occurred within our study area we used the Chilean Forest Inventory (freely available at http://sit.conaf.cl/), which is the most comprehensive and recently updated geodatabase of land-use types of Chile [38]. From this vector-based geodatabase we identified and grouped all the land-use categories that were explicitly indicating a replacement of original natural habitat, including urban areas, industrial areas, mining areas, agriculture lands, and silvicultural lands. All these polygons were grouped under a single category (i.e., land-change) and rasterized in a $100 \mathrm{~m}$ pixel size grid to create a land-change layer resolution that better fit with the $1 \mathrm{~km}^{2}$ Maxent lattice output. This generated layer was then subtracted from the niche modelling layers to map and calculate the extension of habitat loss. Because we did not have an accurate way to estimate the future trends in land-use change, we decide to use a heavily conservative approach to mapping future potential distribution under land-use change by assuming that current distribution and extension of anthropogenic land-use will remain constant.

2.6. Genetic Diversity of Current Populations. We used Inter Simple Sequence Repeat (ISSR, $[39,40])$ to evaluate the level of inter- and intragenetic diversity of current P. splendens populations. We collected samples of young leaves from a total of 121 individuals from three different areas (Table 2). These areas represent the northern, southern, and largest populations for which we found individuals and were taken as three different populations for the genetic analysis. All sampled individuals were georeferenced and their leaves frozen in liquid nitrogen and transported to perform DNA extraction and amplification (through PCR) according to Carrasco et al. [41].

We tested a set of 16 primers (set ISSR 100/8, Biotechnology Laboratory from University of British Columbia, Vancouver), from which five primers were selected to perform the PCR (see Supplementary Material 3). Amplified genetic material was run by electrophoresis (2\% agarose gel) and patterns were visualized and manually recorded (i.e., band presence or absence) for each individual.

We calculated the percentage of polymorphic ISSR loci (P\%) and expected heterozygosity ( $\mathrm{He}$ ) [42] by using GenAlex 6.5 computer software [43]. The relative degree of phenotypic diversity was measured using Shannon's index.

We estimated the genetic differentiation between populations by using AMOVA $\phi_{\text {st }}$ [44]. We also performed a Principal Coordinate Analysis (PCoA) to evaluate the patterns of clustering based on the binary genetic distance displayed by the GenAlex Software [43]. In order to analyze the genetic relationship among sampled individuals, we used the Structure Software Version 2.1 (http://pritchardlab .stanford.edu/structure.html), which is a method that assigns individuals from the entire sample to $k$ clusters in a way that the Hardy Weinberg equilibrium is maximally explained [45]. We used Evanno et al. [46] methodology to estimate the $k$ number of clusters by the Structure Software, using a threshold of 0.8 as the membership probability value $(Q)$ to assign individuals to a specific cluster.

2.7. Assessment of the Conservation Status of P. splendens according to IUCN Criteria. We used the IUCN Red List Categories and Criteria version 3.1 that includes five criteria to assess the species level of threat [47]. The criteria are (a) reduction in population size; (b) small geographic range; (c) small population size and decline; (d) very small or restricted population; and (e) quantitative analysis of extinction risk. We combined existing information with the data generated in our study to reassess the conservation status of P. splendens.

\section{Results}

3.1. P. splendens Population Surveys. After the field campaigns we were able to confirm the current presence of $P$. splendens in only nine sites, which are aligned to the species distribution range reported in the literature. From these, eight correspond to sites previously reported to contain the species, and one corresponds to a site not recorded before. The northern and southern sites correspond to relatively small and isolated populations ( $<100$ individuals), whereas the sites reported between Pichidangui and Los Molles correspond to an apparently relatively large (thousands of individuals) and continuous population (see Supplementary Material 1).

3.2. P. splendens Potential Habitat Modelling. The most relevant bioclimatic variables that explained $P$. splendens habitat distribution are "Minimum Temperature of Coldest Month," "Isothermality," and "Temperature Seasonality," accounting for $62.7 \%, 22.4 \%$, and $14.4 \%$ of the predicted distribution, respectively (Table 1). A performance test for the predicted distribution of $P$. splendens showed that the model has a good predicting performance, with a success of $86 \%(p<0.001)$ for the MSS approach and 76\% $(p<0.001)$ for the 10PL approach. The area for $P$. splendens predicted by the model using both of these approaches is mostly restricted to coastal plains, ravines, and valleys within its historical range. Even though there is a $44.87 \%$ difference in the total predicted suitable habitat (Table 3), both techniques identified three 
TABLE 3: Potential habitat, land-use change, and habitat loss of $P$. splendens under current climatic conditions (years 1950 to 2000 ) and future climate change scenario (RCP 6.0) (years 2041 to 2060) with different thresholds, maximum sensitivity plus specificity (MSS) and 10 percentile training presence $(10 \mathrm{PL})$.

\begin{tabular}{|c|c|c|c|c|c|c|}
\hline \multirow{2}{*}{ Threshold } & \multicolumn{3}{|c|}{ Current } & \multicolumn{3}{|c|}{ Future } \\
\hline & Original (ha) & Land-use change (ha) & Habitat lost (\%) & Original (ha) & Land-use change (ha) & Habitat lost (\%) \\
\hline MSS & 152,016 & 103,297 & 32.05 & 527,417 & 381,146 & 27,73 \\
\hline 10PL & 83,813 & 54,291 & 35.22 & 422,655 & 312,235 & 26,13 \\
\hline Difference (\%) & 44.87 & 47.44 & & 19,86 & 18,08 & \\
\hline
\end{tabular}

main areas that concentrate the large part of suitable habitat. The largest of these areas is located in the central part of the predicted distribution, an intermediate area is located in the southern range, and the smallest is located in the northern section of the distribution (Figure 2).

\subsection{P. splendens Potential Habitat under Climate Change.} Results from the predicted distribution under climate change scenario show that the latitudinal (north-south) range for $P$. splendens is not expected to change much in relation to the predicted distribution under current conditions (Figure 2). However, there is a large effect on the longitudinal extension of populations, with future populations not only located in the coastal range, but also spreading further east through the valleys towards the Chilean central valleys. This increase in distribution also generates an important reduction in the differences between the total potential areas predicted by the two aforementioned approaches when compared to the predicted total area under current climatic conditions (Table 3).

3.4. Estimation of Land-Use Change Effects on P. splendens Potential Distribution. When areas subjected to land-use change are subtracted from maps of potential distribution a clear sign of habitat loss and fragmentation appears (Figure 2). The largest extent of this habitat loss is located in the coastal range of $P$. splendens' potential distribution and is more noticeable in the central and southern range of its distribution. The estimation of habitat loss on potential distribution under current climatic conditions is considerably larger in the MSS approach when compared to the 10PL in absolute values (ha). However, in relative terms the percentage of habitat loss estimated by both approaches is similar, ranging between $32 \%$ and $35 \%$ (Table 3 ).

In the case of projected distribution under future climatic conditions both modelling approaches (i.e., MSS, 10PL) produced similar results (Table 3 ). Because suitable areas under climate change increase more than ten times when compared to current conditions, the total area affected by land-use change is also considerably higher. However, when the effects of land-use change are analyzed in relative terms, the future habitat potentially lost by land-use change is proportionally smaller, with an estimation of $28 \%$ and $26 \%$ approximately for the MSS and 10PL approaches, respectively (Table 3).

3.5. Genetic Diversity of P. splendens. We obtained a total of 157 polymorphic loci with fragments ranging between 260

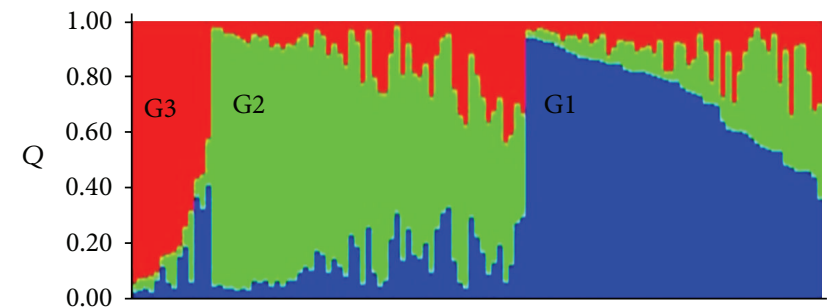

FIgURE 3: Bar plot of $Q$ values for 121 P. splendens individuals analyzed by Structure Software. Three clusters $k$ are shown. Blue cluster (G1) included 23 individuals; green cluster (G2) included 19 individuals; and red cluster (G3) contained 9 individuals. 70 individuals of $P$. splendens did not pertain to any of the three clusters $(Q$ values $<0.8)$.

and 2500 base pairs depending on the used primer. The level of genetic diversity was similar between individuals from the three sampled areas (hereafter populations). The level of polymorphism varied between 98 and 100\% for the studied loci. Heterozygosity and Shannon's diversity index ranged between $0.21-0.24$ and $0.35-0.40$, respectively.

Results from the AMOVA analysis indicated that $97 \%$ of the genetic diversity was distributed within populations, and only a small proportion of genetic diversity could be assigned to differences between populations ( $\phi_{\mathrm{st}}=3 \%, p=0.01$ ). In addition, the Principal Coordinate Analysis (PCoA) did not show any grouping patterns that may reveal presence of genetic differences between sampled populations (data not shown).

The Bayesian clustering analysis performed through the Structure Software using both Evanno et al. [46] and Pritchard et al. [45] criteria resulted in a $k$ number of 3 clusters (Figure 3). The resulting clusters did not show a genetic structure aligned with the spatial distribution of sampled populations. The first cluster included 23 individuals (15 from "Palo Colorado (PC)," 6 from "Pichidangui-Los Molles (PM)," and 2 from the "Caleta Quintay (CQ)" population). The second cluster was comprised of 19 individuals (4 from PC, 7 from PM, and 8 from the CQ population). The third cluster included only nine individuals, all of them from the PM population. The remaining 70 individuals $58 \%$ of sampled individuals) showed $Q$ values lower than 0.8 and therefore were considered as a genetically mixed group.

3.6. Assessment of the Conservation Status of P. splendens according to IUCN Criteria. Results from our study and available information in the literature allow us to evaluate 
TABLE 4: IUCN Red List criteria that apply to P. splendens with description of the information used in the assessment and its applicability in the present study. EOO: extent of occurrence, AOO: area of occupancy, and n: mature individuals (based on Cardoso et al. [69]).

\begin{tabular}{|c|c|c|c|}
\hline Criterion & Subcategory & Information used & Justification/decision \\
\hline $\begin{array}{l}\text { (A) Population reduction } \\
\text { (over } 10 \text { years or three } \\
\text { generations) }\end{array}$ & N/A & None & Insufficient data \\
\hline (B) Geographic range & $\begin{array}{l}\text { B1 } \\
\left(\mathrm{EOO}<5000 \mathrm{~km}^{2} \text { OR }\right. \\
\left.\text { AOO }<500 \mathrm{~km}^{2}\right) \text { AND two } \\
\text { of } \\
\text { (a) fragmentation and/or } \\
\text { locations } \leq 5 \text {; } \\
\text { (b) continuing decline; } \\
\text { (c) extreme fluctuations }\end{array}$ & $\begin{array}{l}\text { (1) Estimation of habitat lost } \\
\text { (2) Genetic diversity analysis } \\
\text { (3) Only two locations left } \\
\text { (4) Estimation of future } \\
\text { declination by future habitat lost } \\
\text { and low natural regeneration [6] }\end{array}$ & $\begin{array}{c}\text { Endangered Blab(i, ii, } \\
\text { iii, iv, v) }\end{array}$ \\
\hline $\begin{array}{l}\text { (C) Small population size } \\
\text { and decline }\end{array}$ & $\mathrm{N} / \mathrm{A}$ & None & Insufficient data \\
\hline $\begin{array}{l}\text { (D) Very small or restricted } \\
\text { population }\end{array}$ & $\begin{array}{l}\mathrm{D} 2 \\
n<1000 \text { OR AOO }< \\
20 \mathrm{~km}^{2} \text { OR locations } \leq 5 \\
\end{array}$ & $\begin{array}{l}\text { Confirmation in situ, estimations } \\
\text { of habitat lost, and available } \\
\text { literature }[2,6]\end{array}$ & $\begin{array}{l}\text { Vulnerable } \\
\text { D2 }\end{array}$ \\
\hline $\begin{array}{l}\text { (E) Quantitative analysis of } \\
\text { extinction risk }\end{array}$ & N/A & None & Insufficient data \\
\hline
\end{tabular}

this species for only three out of the five criteria listed by the IUCN (see Section 2). We could not evaluate criteria (a) and (c) because of the lack of data about generation length. We could not evaluate criterion (e) because we did not have enough data to perform extinction risk analysis such as PVA. Therefore we only assessed P. splendens conservation status by evaluating criteria (b) and (d) (Table 4). To perform the analysis we used the estimated habitat loss presented in Table 3 and the rough estimation of the number of individuals present in the validated sites $(n=1650$; see Supplementary Material 1). We complemented this data with our genetic diversity analyses that suggested that the populations sampled for the analysis were part of one original metapopulation now fragmented. Also, autoecology of the species was considered in the assessment of the level of threat, such as lack of regeneration and seed dispersion constraints (i.e., lack of seed dispersers). In addition, we incorporated references that mentioned threats to $P$. splendens and its habitat (i.e., fires). Moreover, we estimated habitat loss in the next decades in the area of occurrence of $P$. splendens because of the probable development of an urbanization project that potentially will destroy 1700 ha of this species habitat. The results of the threat assessment are summarized in Table 4. Based on our results we classify P. splendens as an Endangered (EN) species.

\section{Discussion}

This study is one of the first efforts to generate landscapelevel knowledge of this species. Furthermore, this is the first attempt to study the distribution of $P$. splendens throughout its current and historical range, and also the first study aiming to evaluate the hypothesis of an original large and continuous population that has been severely reduced and fragmented by historical land-use change. In addition, it is probably the first effort to assess the conservation status of this species by relying on quantitative data.

Increasing the knowledge about understudied taxa with potential conservation problems is a key task for evaluating the real urgency to take conservation actions in the short term [48]. However, this implies several challenges due to the scarcity of available and/or reliable background data. One of the primary challenges we faced in developing this study was the difficulty in finding individuals at locations where historical records show its presence. From a total of 22 historical recorded presence points, we could only validate the presence of $P$. splendens in eight sites. Some of the historic records are very old (e.g., La Palma 1926; see Supplementary Material 1), so we expected that some populations could have gone extinct or have declined in density and extent. Therefore, it is probable that present densities were strongly reduced in some sites, which could preclude us to detect the individuals that were reported in the records. Furthermore, because of the nature of the available records (i.e., historical herbarium lists), some locations were not properly georeferenced and were described simply as a locality or geographic landmark (e.g., "Chivato's ravine"). This probably decreased our success rates of finding individuals representing the populations listed in the historical records. However, we also visited several points not described in the literature that we thought would be suitable for the presence of $P$. splendens, with no individuals found except from one site. The difficulty of finding populations of this species within their historical range of distribution supports the urgent call for conserving remaining populations made by Hechenleitner et al. [2].

4.1. Current and Future Suitable Habitats. The small number of presence records for $P$. splendens was another challenge we had to deal with in our study. Although Maxent has been reported to perform well even with small number of samples 
[26], we took additional actions by tuning the model default setting to optimal levels as this procedure has shown to considerably increase the model performance when dealing with small numbers of presence data [32].

The modelled potential original habitat distribution of $P$. splendens is concentrated in coastal areas between the village of Huentelauquén and the beach resort of Algarrobo, which is in accordance with the historical distribution described by other authors (e.g., $[1,2,7])$. However, the model also generated a small isolated strip of suitable habitat north of Huentelauquén, for which we do not have registers of known populations. Absence of registries for P. splendens in this northern area could be just due to a lack of information because it corresponds to a coastal plain far from towns and roads and of difficult access. However, the area is also coincident with the presence of the Fray Jorge National Park $\left(30^{\circ} 39^{\prime} 50^{\prime \prime} \mathrm{S} ; 71^{\circ} 40^{\prime} 50^{\prime \prime} \mathrm{O}\right)$, for which there are detailed flora inventories (see Squeo et al. [3]), but no registries of $P$. splendens. Therefore, our result from the niche modelling needs to be carefully interpreted, because the lack of other potential important variables in our model (e.g., topography, soil, and dispersion barriers) may result in an overestimation of suitable habitats.

Results from MaxEnt modelling using the climatic change scenario showed that $P$. splendens would spread towards the inland areas of Central Chile, considerably expanding its distribution range in comparison with its distribution under current climate conditions. This trend could be explained because of the increase of temperatures between 2 and $3^{\circ} \mathrm{C}$ that is projected to occur in Central Chile due to climate change [11, 49]. The Pouteria genus has a tropical origin [50] and P. splendens is considered a relict species from an ancient warmer climate $[24,51]$. Therefore, as temperature of the coldest month is the most important variable for this species, climate change may increase this temperature in inland territories, increasing potential suitable areas for this species in the future.

The projected potential distribution under climate change may overestimate the suitable areas for $P$. splendens because our model did not account for the effect of the marine fog commonly present in these coastal areas. Marine fog may have an important influence in the viability of $P$. splendens populations since it provides a relatively constant source of water $[1,2,6]$. One way to account for the fog effect influence could be to include the distance to the coast in the modelling. However, we think that due to the complex topography and wind currents that prevail in the area assessed it is difficult to directly relate the fog influence with the distance to the coast. In fact in this zone the fog does not occur in the entire coastal range, but only in some specific places that have wind patterns conducting the humidity to inland mountains where air rises and condensation occurs. Furthermore there is an important fog interannual variability that is affected by the ENSO cycles, which could make it even more difficult to estimate its real potential presence in the future [52]. Though, we think that this is a very interesting and challenging subject that needs to be covered by further researches.

Projected climate change is supposed to reduce precipitation in inland areas of Central Chile [11,49], which may reduce the germination rates of this species [7]. Therefore, we expect that the suitable areas will increase under a climate change scenario, but probably in a smaller extent than the shown by the niche model.

In terms of the effects of land-use change in P. splendens distribution, our results show that the current potential habitat distribution is at least $30 \%$ smaller than the original potential distribution. This percentage of potential habitat loss appears not to be so substantial if we take into account that this land-use change started more than 200 years ago and that today nearly one million people live within this area. However, maps show that land-use change has also resulted in high levels of habitat fragmentation, which together with habitat loss are considered as the main causes of biodiversity loss in Mediterranean habitats $[53,54]$.

Fragmentation of the original habitats imposes new conditions to the remaining communities, increasing edge effect and reducing the core area suitable for species [55-57]. Furthermore, in Central Chile fragmentation can increase the frequency of disturbances by fires $[10,58]$. Therefore, even though the modelled potential distribution suggests that between 65 and $67 \%$ of the areas suitable for $P$. splendens still are considered as remaining natural habitats, the additional effect of fragmentation may have caused an extreme reduction of the original populations. These current levels of habitat fragmentation also suggest that even assuming that under the future climate scenario suitable habitats for $P$. splendens will increase, barriers to dispersion may restrict the colonization processes $[6,59]$.

4.2. Genetic Diversity. The analysis of Inter Simple Sequence Repeat (ISSR) diversity revealed that remaining $P$. splendens populations still maintain a high level of intrapopulation genetic diversity. The genetic variability values for $P$. splendens were similar to those reported by Nybom [60] for plants species using dominant molecular markers and are consistent with values observed for other perennial-endemicallogamous-animal-dispersed species [60]. In relation to the interpopulation genetic diversity, the low levels of genetic differentiation between populations detected by AMOVA $\left(\phi_{\text {st }}=0.03\right)$ are notably lower than those observed for other plants species using dominant markers [60] and also for populations of other natives Chilean tree species such as Araucaria araucana $\left(\phi_{\mathrm{st}}=0.13 ;[61]\right)$ and Pilgerodendron uviferum $\left(\phi_{\text {st }}=0.19 ;[62]\right)$. The large intra- and small interpopulation genetic variability was also supported by the results from the Bayesian model-based clustering analysis. The analysis suggests the presence of three main clusters; however only $42 \%$ of the total analyzed individuals were assigned to a cluster, whereas the remaining 58\% did not present enough genetic differences to be considered as part of any of the three clusters and therefore were considered as a mixed group.

Naturally rare or narrowly distributed plant species generally maintain lower within and higher between population genetic diversity than widespread species $[63,64]$; however this was not the case for P. splendens. Among the main factors explaining a high genetic diversity in rare plant species are the recent reduction and isolation of populations 
or the presence of specific mechanisms that promote gene flow between populations, such as animal or wind mediated outcrossing pollination and seed dispersal $[65,66]$. In the case of $P$. splendens there is no available information about the pollination mechanism, but observation from other Pouteria species reports self-pollination and insect-mediated pollination [67]. None of these mechanisms could explain the genetic diversity patterns found within and between $P$. splendens populations. In relation to seed dispersal, the fruit size (2-3 cm in diameter, [2]) suggests that seed dispersal of $P$. splendens is probably mediated by large animals [7]. However, the long extirpation of large animals from the actual range of $P$. splendens distribution makes it improbable that this mechanism could be related to the genetic diversity of current populations.

Therefore, the high level of genetic variability within populations, the admixture patterns, and the weak genetic structure between populations suggest that current $P$. splendens populations might be the result of a recent process of loss and habitat fragmentation. As time since fragmentation is a key factor related to the loss of genetic diversity in isolated populations [64], we may expect to see a decrease in intraand an increase in interpopulation genetic diversity of $P$. splendens in the future and therefore a potential increase of vulnerability to extinction of remaining populations.

4.3. Conservation Status. Our assessment of the level of threat of $P$. splendens using the IUCN criteria revealed that, based on our data, this species should be reclassified as Endangered. Our results differ from Hechenleitner et al. [2] who classified P. splendens as Critically Endangered (Blab(iii)). Unfortunately, we cannot compare our results to Hechenleitner et al. [2] as they did not report what information they used to perform their assessment.

We could not calculate or find reliable data to estimate the area of occupancy of the species. Although there is data from the national forest inventory that could help to estimate an area of occupancy, it seems that the inventory did not include accurate data at the species level, and only three sites containing $P$. splendens were apparently mapped, representing an extension no larger than 400 ha. In contrast, based in our field survey we presume that the area of occupancy is not smaller than 2.000 ha. However, even taking an optimistic approach of 3.000 ha for the area of occupancy, this would not change $P$. splendens to any other conservation status (e.g., from Endangered to Vulnerable) because other assessment criteria will prevail.

We had a similar challenge for estimating the size of the remaining populations. We only could calculate densities of $P$. splendens based on roughly estimation performed in each of the visited sites. Thus, these estimations corresponded to projected abundance for the specific visited site but do not reflect an estimation for the entire population at that point, and therefore they cannot be used to calculate the total number of individuals present in the range of distribution. However, as what happened with the area of occupancy variable, the classification of $P$. splendens as Endangered is not based on the lower number of individuals we were able to estimate, but on other assessment criteria. Therefore, even though further studies are able to estimate larger population's size, the threat level of $P$. splendens would not change.

\section{Conclusions}

Results from our work provide new and essential information for assessing current conservation status of $P$. splendens populations. The integration of our results (i.e., niche modelling, land-use change estimation, and genetic variability analysis) suggests that $P$. splendens had a large continuous population that extended through the entire range of historical recorded populations, providing essential evidence to support the continuous population assumption made previously by other authors (e.g., [1, 2]).

We were also able to update information regarding the current populations, establishing that there are only two main areas with $P$. splendens populations left, as was also suggested by previous studies. However, we found that these remaining populations are more reduced in extension and density that was previously thought. Moreover, the largest and best preserved of these populations (i.e., PichidanguiLos Molles) is currently heavily threatened by anthropogenic pressures, including goat grazing, exotic tree plantations, illegal trash dumping, increasing fires, and real-estate developments. Although this area has been declared as an Urgent Priority Site for Conservation by the Chilean government [13], until now, there has not been any official conservation action taken. More concerning is the fact that currently the local government is soon to officialize a new urban development normative, which is proposing to transform more than 1700 ha of the Los Molles-Pichidangui P. splendens population habitat, from natural, to residential land-use [68]. Because of this probable habitat loss, $P$. splendens may soon change its conservation status from Endangered to Critically Endangered.

Based on the results from our work we recommend (1) updating the information available to the IUCN and reclassifying $P$. splendens as Endangered, (2) taking urgent public and private actions to conserve the remaining populations of $P$. splendens, especially the larger populations which are now threatened by an imminent change in the land-use normative, and (3) developing more studies to fill the knowledge gap regarding this species.

\section{Conflict of Interests}

The authors declare that there is no conflict of interests regarding the publication of this paper.

\section{Acknowledgments}

The authors would like to thank Miguel Gómez from the Faculty of Agronomy and Forestry Engineering of the Pontifical Catholic University of Chile for his assistance in collecting historical presence data. The authors also would like to thank Giselle Muschett for their help refining previous version of the paper. Fieldwork and the genetic analysis were funded by the Chilean Native Forest Research Grant, 
Project CONAF 025/2010: “Distribución, Hábitat Potencial y Diversidad Genética de Poblaciones de Belloto del Norte (Beilschmiedia miersii) y Lúcumo Chileno (Pouteria splendens)."

\section{References}

[1] M. Muñoz and M. Serra, Estado de Conservación de las Plantas de Chile. Documento de Trabajo, vol. 113, Museo Nacional de Historia Natural y Comisión Nacional del Medio Ambiente (MNHN-CONAMA), 2006.

[2] P. Hechenleitner, M. F. Gardner, P. I. Thomas et al., Plantas Amenazadas del Centro-Sur de Chile: Distribución, Conservación y Propagación, Universidad Austral de Chile, Valdivia, Chile, 2005.

[3] F. Squeo, G. Arancio, and J. Gutiérrez, Libro Rojo de la Flora Nativa y de los Sitios Prioritarios para su Conservación: Región de Coquimbo, Ediciones Universidad de La Serena, La Serena, Chile, 2001.

[4] Ministerio de Medio Ambiente de Chile, "Inventario Nacional de Especies," 2014, http://especies.mma.gob.cl/CNMWeb/Web/ WebCiudadana/Default.aspx.

[5] IUCN, "IUCN Red List of Threatened Species. Version 2014.3," 2015, http://www.iucnredlist.org/.

[6] C. A. Henríquez, G. J. Sotes, and R. O. Bustamante, "Fenología reproductiva de Pouteria splendens (Sapotaceae)," Gayana Botánica, vol. 69, no. 2, pp. 251-255, 2012.

[7] G. Sotes, R. O. Bustamante, and C. Henríquez, "Distribución de plántulas y germinación de semillas del lúcumo chileno (Pouteria splendens) en Los Molles, Chile," Revista Chilena de Historia Natural, vol. 88, no. 3, pp. 337-344, 2013.

[8] J. M. Quintana and P. Aceituno, "Changes in the rainfall regime along the extratropical west coast of south America (Chile): 30 $43^{\circ}$ S," Atmosfera, vol. 25, no. 1, pp. 1-22, 2011.

[9] N. Schulz, J. P. Boisier, and P. Aceituno, "Climate change along the arid coast of northern Chile," International Journal of Climatology, vol. 32, no. 12, pp. 1803-1814, 2012.

[10] G. Montenegro, R. Ginocchio, A. Segura, J. E. Keely, and M. Gómez, "Fire regimes and vegetation responses in two Mediterranean-climate regions," Revista Chilena de Historia Natural, vol. 77, no. 3, pp. 455-464, 2004.

[11] CONAMA, Estudio de la Variabilidad Climática en Chile para el Siglo XXI: Informe Final, Departamento de Geofísica de la Facultad de Ciencias, Físicas y Matemáticas, Universidad de Chile, Santiago, Chile, 2006.

[12] A. Lammi, P. Siikamäki, and K. Mustajärvi, "Genetic diversity, population size, and fitness in central and peripheral populations of a rare plant Lychnis viscaria," Conservation Biology, vol. 13, no. 5, pp. 1069-1078, 1999.

[13] CONAMA-PNUD, Estrategia y Plan de Acción para la Conservación de la Diversidad Biológica: Región de Valparaíso, CONAMA-PNUD, Valparaíso, Chile, 2005, http://www.sinia .cl/1292/articles-37028_pdf_valpo.pdf.

[14] G. J. Sotes, A. Urzúa, and B. Sebastián, "Chemistry of Pouteria splendens and its ecological situation," Biochemical Systematics and Ecology, vol. 34, no. 4, pp. 338-340, 2006.

[15] P. B. Nuñez, Manipulación de semillas y producción de plantas de lúcumo silvestre (Pouteria splendens (A.DC.) O.K.) [Forest Engineering Professional Degree], Facultad de Ciencias Forestales, Universidad de Chile, Santiago, Chile, 2005.
[16] S. J. Phillips, R. P. Anderson, and R. E. Schapire, "Maximum entropy modeling of species geographic distributions," Ecological Modelling, vol. 190, no. 3-4, pp. 231-259, 2006.

[17] S. J. Phillips and M. Dudík, "Modeling of species distributions with Maxent: new extensions and a comprehensive evaluation," Ecography, vol. 31, no. 2, pp. 161-175, 2008.

[18] R. G. Mateo, Á. M. Felicísimo, and J. Muñoz, "Species distributions models: a synthetic revision," Revista Chilena de Historia Natural, vol. 84, no. 2, pp. 217-240, 2011.

[19] R. Frankham, "Genetics and extinction," Biological Conservation, vol. 126, no. 2, pp. 131-140, 2005.

[20] J. Freeland, Molecular Ecology, John Wiley \& Sons, Chichester, UK, 2005.

[21] P. Opdam and D. Wascher, "Climate change meets habitat fragmentation: linking landscape and biogeographical scale levels in research and conservation," Biological Conservation, vol. 117, no. 3, pp. 285-297, 2004.

[22] F. Luebert and P. Pliscoff, Sinopsis Bioclimática y Vegetacional de Chile, Editorial Universitaria, Santiago, Chile, 2006.

[23] Dirección Meteorológica de Chile, "Climatología Regional," 2001, http://164.77.222.61/climatologia/publicaciones/Climatologia_regional.pdf.

[24] R. Gajardo, La Vegetación Natural de Chile: Clasificación y Distribución Geográfica, Editorial Universitaria, Santiago, Chile, 1994.

[25] J. Elith, C. H. Graham, R. P. Anderson et al., "Novel methods improve prediction of species' distributions from occurrence data," Ecography, vol. 29, no. 2, pp. 129-151, 2006.

[26] R. G. Pearson, C. J. Raxworthy, M. Nakamura, and A. Townsend Peterson, "Predicting species distributions from small numbers of occurrence records: a test case using cryptic geckos in Madagascar," Journal of Biogeography, vol. 34, no. 1, pp. 102-117, 2007.

[27] R. J. Hijmans, S. E. Cameron, J. L. Parra, P. G. Jones, and A. Jarvis, "Very high resolution interpolated climate surfaces for global land areas," International Journal of Climatology, vol. 25, no. 15, pp. 1965-1978, 2005.

[28] C. Merow, M. J. Smith, and J. A. Silander, "A practical guide to MaxEnt for modeling species' distributions: what it does, and why inputs and settings matter," Ecography, vol. 36, no. 10, pp. 1058-1069, 2013.

[29] D. L. Warren, R. E. Glor, and M. Turelli, "ENMTools: a toolbox for comparative studies of environmental niche models," Ecography, vol. 33, no. 3, pp. 607-611, 2010.

[30] D. L. Warren and S. N. Seifert, "Ecological niche modeling in Maxent: the importance of model complexity and the performance of model selection criteria," Ecological Applications, vol. 21, no. 2, pp. 335-342, 2011.

[31] M. M. Syfert, M. J. Smith, and D. A. Coomes, "The effects of sampling bias and model complexity on the predictive performance of maxent species distribution models," PLoS ONE, vol. 8, no. 2, Article ID e55158, 2013.

[32] M. Shcheglovitova and R. P. Anderson, "Estimating optimal complexity for ecological niche models: a jackknife approach for species with small sample sizes," Ecological Modelling, vol. 269, pp. 9-17, 2013.

[33] C. Liu, P. M. Berry, T. P. Dawson, and R. G. Pearson, "Selecting thresholds of occurrence in the prediction of species distributions," Ecography, vol. 28, no. 3, pp. 385-393, 2005.

[34] R. Contreras-Medina, I. Luna-Vega, and C. A. Ríos-Muñoz, "Distribución de Taxus globosa (Taxaceae) en México: modelos 
ecológicos de nicho, efectos del cambio del uso de suelo y conservación," Revista Chilena de Historia Natural, vol. 83, no. 3, pp. 421-433, 2010.

[35] C. G. Vale, P. Tarroso, and J. C. Brito, "Predicting species distribution at range margins: testing the effects of study area extent, resolution and threshold selection in the Sahara-Sahel transition zone," Diversity and Distributions, vol. 20, no. 1, pp. 20-33, 2014.

[36] C. D. Jones, J. K. Hughes, N. Bellouin et al., "The HadGEM2ES implementation of CMIP5 centennial simulations," Geoscientific Model Development, vol. 4, no. 3, pp. 543-570, 2011.

[37] R. H. Moss, J. A. Edmonds, K. A. Hibbard et al., "The next generation of scenarios for climate change research and assessment," Nature, vol. 463, no. 7282, pp. 747-756, 2010.

[38] CONAF, Catastro de los Recursos Vegetacionales Nativos de Chile, Lom Ediciones, Santiago, Chile, 2011.

[39] M. Gupta, Y.-S. Chyi, J. Romero-Severson, and J. L. Owen, "Amplification of DNA markers from evolutionarily diverse genomes using single primers of simple-sequence repeats," Theoretical and Applied Genetics, vol. 89, no. 7-8, pp. 998-1006, 1994.

[40] E. Zietkiewicz, A. Rafalski, and D. Labuda, "Genome fingerprinting by simple sequence repeat (SSR)-anchored polymerase chain reaction amplification," Genomics, vol. 20, no. 2, pp. 176$183,1994$.

[41] B. Carrasco, M. Garcés, P. Rojas et al., "The chilean strawberry [Fragaria chiloensis (L.) Duch.]: genetic diversity and structure," Journal of the American Society for Horticultural Science, vol. 132, no. 4, pp. 501-506, 2007.

[42] M. Nei, "Analysis of gene diversity in subdivided populations," Proceedings of the National Academy of Sciences of the United States of America, vol. 70, no. 12, pp. 3321-3323, 1973.

[43] R. Peakall and P. E. Smouse, "GenALEx 6.5: genetic analysis in Excel. population genetic software for teaching and researchan update," Bioinformatics, vol. 28, no. 19, pp. 2537-2539, 2012.

[44] L. Excoffier, P. E. Smouse, and J. M. Quattro, "Analysis of molecular variance inferred from metric distances among DNA haplotypes: application to human mitochondrial DNA restriction data," Genetics, vol. 131, no. 2, pp. 479-491, 1992.

[45] J. K. Pritchard, M. Stephens, and P. Donnelly, "Inference of population structure using multilocus genotype data," Genetics, vol. 155, no. 2, pp. 945-959, 2000.

[46] G. Evanno, S. Regnaut, and J. Goudet, "Detecting the number of clusters of individuals using the software structure: a simulation study," Molecular Ecology, vol. 14, no. 8, pp. 2611-2620, 2005.

[47] International Union for Conservation of Nature, IUCN Red List Categories and Criteria: Version 3.1, International Union for Conservation of Nature (IUCN), Gland, Switzerland, 2001.

[48] M. L. McKinney, "High rates of extinction and threat in poorly studied taxa," Conservation Biology, vol. 13, no. 6, pp. 1273-1281, 1999.

[49] M. N. Nũez, S. A. Solman, and M. F. Cabré, "Regional climate change experiments over southern South America. II: climate change scenarios in the late twenty-first century," Climate Dynamics, vol. 32, no. 7, pp. 1081-1095, 2009.

[50] C. A. M. Silva, L. A. Simeoni, and D. Silveira, "Genus Pouteria: chemistry and biological activity," Brazilian Journal of Pharmacognosy, vol. 19, no. 2, pp. 501-509, 2009.

[51] J. Francois, "Eslabones de una cadena rota: el caso del bosque relicto de Santa Inés," in Historia Natural del Parque Nacional Bosque de Fray Jorge, pp. 205-218, Corporación Nacional Forestal, Santiago, Chile, 2004.
[52] R. Garreaud, J. Barichivich, D. A. Christie, and A. Maldonado, "Interannual variability of the coastal fog at Fray Jorge relict forests in semiarid Chile," Journal of Geophysical Research: Biogeosciences, vol. 113, Article ID G04011, 2008.

[53] I. N. Vogiatzakis, A. M. Mannion, and G. H. Griffiths, "Mediterranean ecosystems: problems and tools for conservation," Progress in Physical Geography, vol. 30, no. 2, pp. 175-200, 2006.

[54] S. D. Cooper, P. S. Lake, S. Sabater, J. M. Melack, and J. L. Sabo, "The effects of land use changes on streams and rivers in mediterranean climates," Hydrobiologia, vol. 719, no. 1, pp. 383425, 2013.

[55] L. Fahrig, "Effects of habitat fragmentation on biodiversity," Annual Review of Ecology, Evolution, and Systematics, vol. 34, pp. 487-515, 2003.

[56] R. M. Ewers and R. K. Didham, "Confounding factors in the detection of species responses to habitat fragmentation," Biological Reviews, vol. 81, no. 1, pp. 117-142, 2006.

[57] R. M. Ewers, S. Thorpe, and R. K. Didham, "Synergistic interactions between edge and area effects in a heavily fragmented landscape," Ecology, vol. 88, no. 1, pp. 96-106, 2007.

[58] I. C. Fernández, N. S. Morales, L. A. Olivares, J. A. Salvatierra, M. U. Gómez, and G. R. Montenegro, Restauracion Ecológica para Ecosistemas Nativos Afectados por Incendios Forestales, Pontificia Universidad Católica de Chile, Santiago, Chile, 2010.

[59] R. Engler and A. Guisan, "MigClim: predicting plant distribution and dispersal in a changing climate," Diversity and Distributions, vol. 15, no. 4, pp. 590-601, 2009.

[60] H. Nybom, "Comparison of different nuclear DNA markers for estimating intraspecific genetic diversity in plants," Molecular Ecology, vol. 13, no. 5, pp. 1143-1155, 2004.

[61] S. A. Bekessy, T. R. Allnutt, A. C. Premoli et al., "Genetic variation in the vulnerable and endemic Monkey Puzzle tree, detected using RAPDs," Heredity, vol. 88, no. 4, pp. 243-249, 2002.

[62] T. R. Allnutt, A. C. Newton, A. Premoli, and A. Lara, "Genetic variation in the threatened South American conifer Pilgerodendron uviferum (Cupressaceae), detected using RAPD markers," Biological Conservation, vol. 114, no. 2, pp. 245-253, 2003.

[63] M. A. Gitzendanner and P. S. Soltis, "Patterns of genetic variation in rare and widespread plant congeners," American Journal of Botany, vol. 87, no. 6, pp. 783-792, 2000.

[64] R. Aguilar, M. Quesada, L. Ashworth, Y. Herrerias-Diego, and J. Lobo, "Genetic consequences of habitat fragmentation in plant populations: susceptible signals in plant traits and methodological approaches," Molecular Ecology, vol. 17, no. 24, pp. 5177-5188, 2008.

[65] S. Luan, T.-Y. Chiang, and X. Gong, "High genetic diversity vs. low genetic differentiation in Nouelia insignis (Asteraceae), a narrowly distributed and endemic species in China, revealed by ISSR fingerprinting," Annals of Botany, vol. 98, no. 3, pp. 583589, 2006.

[66] M. A. Millar, D. J. Coates, and M. Byrne, "Extensive longdistance pollen dispersal and highly outcrossed mating in historically small and disjunct populations of Acacia woodmaniorum (Fabaceae), a rare banded iron formation endemic," Annals of Botany, vol. 114, no. 5, pp. 961-971, 2014.

[67] M. Jordan, "Pouteria species," in Trees IV, Y. Bajaj, Ed., vol. 35 of Biotechnology in Agriculture and Forestry, pp. 291-307, Springer, Berlin, Germany, 1996.

[68] Seremi Medio Ambiente Valparaíso, "Oficio N $\mathrm{N}^{\circ} 33 / 2014$," Cámara de Diputados de Chile, Valparaiso, Chile, 2014, 
http://www.camara.cl/pdf.aspx?prmTIPO=DOCUMENTOCOMISION\&prmID=20881.

[69] P. Cardoso, P. A. V. Borges, K. A. Triantis, M. A. Ferrández, and J. L. Martín, "Adapting the IUCN Red List criteria for invertebrates," Biological Conservation, vol. 144, no. 10, pp. 2432-2440, 2011. 

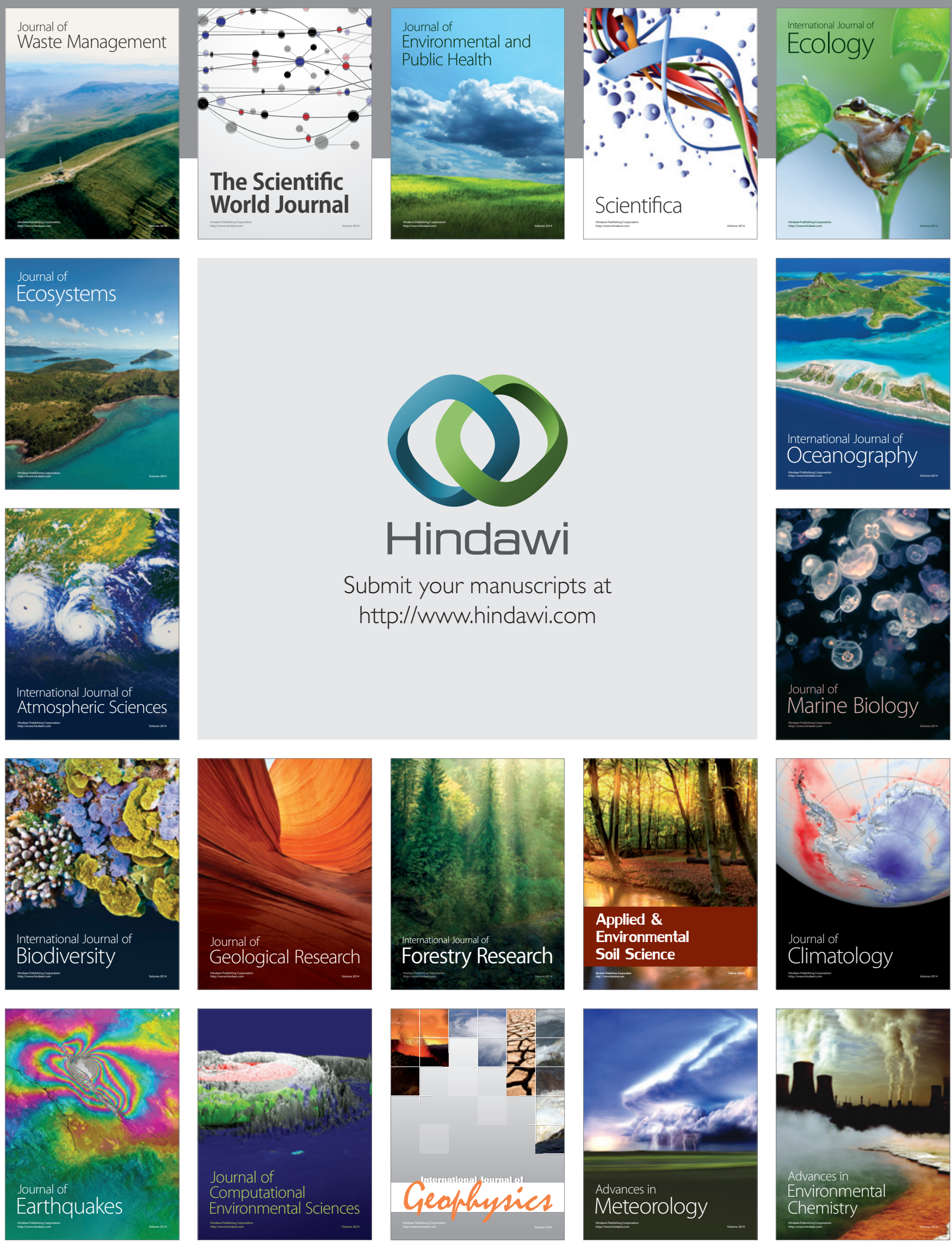